\title{
QSAR-МОДЕЛИРОВАНИЕ ИНГИБИТОРОВ ЦИКЛООКСИГЕНАЗЫ-2 В РЯДУ НЕКОТОРЫХ АЗОТ- И КИСЛОРОДСОДЕРЖАЩИХ ДИАРИЛГЕТЕРОЦИКЛИЧЕСКИХ СОЕДИНЕНИЙ
}

\author{
Ю.З. Мартынова, В.Р. Хайруллина, А.Г. Мустафин \\ Химический факультет, Башкирский государственный университет, \\ 450076, Россия, Уфа, ул. Заки Валиди, д. 32.
}

DOI: 10.19163/MedChemRussia2021-2021-541

E-mail: MartynovaYuZ@gmail.com

Целью данной работы было установление количественной связи «структура-ингибиторная активность» в ряду диарилгетероциклических производных в отношении циклооксигеназы-2 (ЦОГ-2) человека, экспериментально изученных в работе [1], и построение моделей QSAR на основе этих классов соединений для виртуального скрининга виртуальных библиотек и баз данных. Исследования проводили с использованием программы GUSAR 2019 по методике, описанной в работах [2]. С использованием метода RBF-SCR, заложенного в программе GUSAR 2019, на основе QNA- и MNA-дескрипторов [2], а также их сочетания, построено шесть статистически значимых устойчивых консенсус моделей QSAR прогноза численных значений $\mathrm{IC}_{50}$ для моделируемых соединений. Каждая из консенсус-моделей включала в себя от 20 до 320 частных QSAR-уравнений со статистическими параметрами $\mathrm{R}^{2}>0.7 ; \mathrm{Q}^{2}>0.6$ (таблица 1). Эти модели применимы для виртуального скрининга и поиска новых соединений с выраженной ингибиторной активностью в отношении ЦОГ-2 с целью разработки новых ингибиторов данного фермента.

Табл. 1

Статистические характеристики консенсус-моделей M1-M6

\begin{tabular}{|c|c|c|c|c|c|c|c|c|}
\hline OB & Модель & $\mathrm{N}$ & $\mathrm{R}_{\mathrm{OB}}^{2}$ & $\mathrm{R}_{\mathrm{TB}}^{2}$ & $\mathrm{~F}$ & S.D. & $Q^{2}$ & V \\
\hline \multicolumn{9}{|c|}{ Модели QSAR, построенные на основе QNA-дескрипторов } \\
\hline OB1 & M1 & 255 & 1.000 & 0.702 & 10.598 & 0.502 & 0.713 & 46 \\
\hline OB2 & M4 & 213 & 1.000 & 0.717 & 8.975 & 0.515 & 0.702 & 41 \\
\hline \multicolumn{9}{|c|}{ Модели QSAR, построенные на основе MNA-дескрипторов } \\
\hline OB1 & M2 & 255 & 0.995 & 0.705 & 11.046 & 0.460 & 0.762 & 51 \\
\hline OB2 & M5 & 213 & 1.000 & 0.685 & 10.793 & 0.473 & 0.750 & 41 \\
\hline \multicolumn{9}{|c|}{ Модели QSAR, построенные на основе QNA- и MNA-дескрипторов } \\
\hline OB1 & M3 & 255 & 0.998 & 0.717 & 11.626 & 0.468 & 0.754 & 46 \\
\hline OB2 & M6 & 213 & 1.000 & 0.726 & 10.424 & 0.486 & 0.739 & 38 \\
\hline
\end{tabular}

где $\mathrm{N}$ - число структур в OB; $\mathrm{R}_{\text {ов }}$ - коэффициент детерминации, рассчитанный для соединений из ОВ; $\mathrm{R}_{\text {TВ }}^{2}$ - коэффициент детерминации, рассчитанный для соединений из ТВ, $\mathrm{Q}^{2}$ - коэффициент детерминации, рассчитанный для ОВ при скользящем контроле с исключением по одному; F - критерий Фишера; S.D. - стандартное отклонение; V - число переменных в конечном регрессионном уравнении.

Работа выполнена при поддержке гранта №19-73-20073 Российского научного фонда

\section{Литература}

[1] P. Chavatte, S. Yous and et.al., Journal of Medicinal Chemistry. 2001, 44, 3223-3230.

[2] V. Khairullina, I. Safarova, G. Sharipova, Y. Martynova, A. Gerchikov Molecules. 2021, 26, 421.

$$
-541-
$$

